\title{
Educational Sustainable Development: the New Research Topic of National Demonstration Higher Vocational Education
}

\author{
Zhigang $\mathrm{YU}^{1, \mathrm{a}^{*}}$, Rongrong $\mathrm{CHEN}^{2, \mathrm{~b}}$ \\ ${ }^{1}$ School of Architecture Engineering, Chongqing Vocational Institute of Engineering, Chongqing 402260, \\ China \\ ${ }^{2}$ School of Marxism, Chongqing Technology and Business University, Chongqing 400067, China \\ aemail: yzg3@sina.com, bemail: crr3@sina.com
}

Keywords: Demonstration; Reform and innovation; Sustainable education; Regional education; Higher vocational education.

\begin{abstract}
Sustainable education is an important way to build a harmonious campus. Around the development of National Demonstration Higher Vocational Colleges, the paper puts forward several aspects of the reform and innovation of the higher vocational education and analyses the current situation of vocational college in our country and puts forward specific advice of strengthening "sustainable" education, deepening "sustainable" consciousness, carrying out the sustained development of higher vocational education.
\end{abstract}

\section{Introduction}

In 1987, the world environment and Development Committee (WCED) defined sustainable development in the report of our common future:It not only meet the needs of moderns, but also without compromising the ability of future generations to meet their needs. It affirm that develop is the necessary premise, taking the interests of the contemporary people and the offspring into account,it is the integration of the resources, the environment and the positive attitude towards development [1]. China has already regarded the sustainable development as the social development strategy, and the education in the sustainable development strategy should have the idea of "development" firstly.

Sustainable development of education requires overall consideration between the national policy, economic condition and education development.Promoting their coordination and achieve the goal of development of people,education and society. "If the people lack of a wide range of modern psychological basis that can give these systems a real vitality, if the people who use these modern technologies not ready for a transition to a modern psychological and ideological attitudes and behavior, it is inevitable that the failure and abnormal development of the tragic ending is coming." says the American scholar Alex Ingalls. Considering the current national demonstrative higher vocational school construction, this paper presents several aspects of the higher vocational education reform and innovation, analysis the present situation of the higher vocational colleges in our country and put forward an idea of strengthening the "sustainable" education, deepening the "sustainable" consciousness, raising several suggestions for realizing the sustainable development of Higher Vocational education.

\section{Harmonious campus should have these characteristics}

Fully develop socialist democracy, the law school has been effectively implemented; the interests of all sides are properly coordinated, faculty internal contradictions and other contradictions are handled correctly, fairly maintained and achieve justice; the entire group are helping each other, full of honest and trustworthy people, they are equality and fraternity, they live in harmony; respect for labor, respect knowledge, respect talent, creativity, all positive factors to get the most extensive and fully mobilized and excite dynamic categories of 
personnel, all the creative aspirations that can in favor of school development, social progress and creativity, creative talent, creative achievements are respected, supported, loved and affirmed, schools full of vigor and vitality; school organizational mechanisms sound science, sound management, campus are on good order, the students are developing comprehensively. staff live and work happily, schools are stable and unit; faculty and campus, campus and social are in harmony, civilized and healthy. Schools are cultivating qualified personnel for the country and make contributing to scientific research, promoting social productivity's improvement and development of advanced culture, giving better services for the majority of the people [2]; Education develop steadily, sustainable and healthy.

\section{Status for Vocational Education}

The current national strategy is to develop the vocational colleges vigorously. The object of our education is the third undergraduate batches. The character for them is the weak on basic cultural knowledge, poor self-control ability and self-cultivation. The main course should be the disharmony between family education and school education, long-term bad habits and unclear world view, the outlook on life and the sense of worth.

Chinese former Minister of Education Zhou Ji emphasize the Vocational Education in the Third National Experience Exchange Conference that the main task of vocational education is to train the skilled talent. He said that such kind of people, neither called by white nor blue-collar. It's the applicable-type white-collar workers. We could call them "silver collar." Zhou Ji noted that students of vocational education should be trained both mental and physical skill. But also to be able to get involved in practice. They could grow up to skilled talent rapidly.

\section{Innovation for Vocational Education}

A major trend for the modern education is the education in daily life and lively education. That's the re-combine for education and daily life. Education in daily life means education should focus on student's life. To link their life world. The lively education means that make student get education from their daily life. Should pay attention to students' educational situations. So that students could be educated in their normal life[3]. This is the new conception for education. Based on the national vocational colleges constructing strategy. Following aspects could be strengthen the innovation.

Making Vocational Educational More Regional. Higher vocational colleges are mainly aimed at driving the local economies and providing them with fast-growing high-skilled talents.

Through the study of the regional society's politics, economy, population and culture, we can predict the influence the changes of the regional economic structure have on the structure of the regional vocational education, predict quite precisely the supply and the demand of the regional vocational education so as to make a scientific planning of the regional vocational education's structure, scale, development speed, system, curriculum, organizational forms, and teaching methods and means, and to speed up the development of higher vocational education in various areas[4].

Strengthen the humanistic quality education. There is the phenomena that emphasizes specialty, neglects quality and emphasizes education, neglects moral education in the vocational education of our country to varying degrees, because of the traditional way of thinking[5,6]. Higher vocational students mainly come from the third batch of the college entrance examination, most of which graduate from vocational colleges, colleges and technical schools ,therefore, It is not hard for us to realize that it is necessary to strengthen the humanistic education in the higher vocational colleges to make the students develop comprehensively and have a perfect personality.

The law and characteristics of higher vocational education is to cultivate more applied expertise with the high quality and high grade technology which can meet market and social needs, and they can do difficult things, 
apply theory into practice, stand their ground, acquire and apply techniques readily, and have strong adaptability. Therefore, the heart of characteristics higher vocational education lies in "education". Strengthening humanistic quality can improve the overall quality of the students comprehensively, and it is also good to students to improve the ideological level, elevate personality, broaden the vision, active thinking, inspire innovation, and arouse the creativity.

Strengthen the innovative thinking of Education. In the era of knowledge economy, we recognize that the ability to acquire knowledge is more important than knowledge itself, and the method of acquiring information is more important than the information itself. For higher vocational education, we must as soon as possible to reform and adjust the teaching mode and method, even the curriculum and teaching materials, so as to enable our higher vocational education to go with the development of the times and adapt to the arrival of the knowledge economy society.

The so called innovative learning is to make education a source of cultivating creative spirit and stimulating the creativity, which is not only to teach students the ready-made knowledge, but also to guide them to explore the unknown, let the students not only receive ready answers to solve the problem, but find a unique approach to solve problem[7]. The goal of emphasizing the cultivation of entrepreneurial ability of students is to make graduates thrive more easily, and make graduates not only become qualified job hunters, but also become entrepreneurs[8]. Colleges and universities should attach great importance to the cultivation of students for analysis ability of complex problem, initiative, responsibility, especially to pay attention to the cultivation of innovation ability, growth ability in practice, in this case, they can be devoted to labor market freely after graduation[9].

\section{The suggestions for higher occupational education}

The class management. In most classes, there is only one headteacher, who serves as the principal manager; While there is far rarer phenomenon that the professional counselor governs the class. This modal epitomizes the secondary technical school with Chinese characters. In china at the end of last century plenty of secondary technical schools upgrade into junior colleges, since then they have been always striving to promote the managing levels progressively.It is hopeful that the junior colleges will possess professional counselor teams in the near future. Since constructing a representative school means the precedence in management,only through the way of improving management can reveal the features of "representative" and "higher"in the representative higher occupational school.

We should explore the new ways as following: First, carry an experiment that the representative research program of student management debuts. second, the class manager switches from a headteacher to a professional counselor, which massively improves the school's management. Third, the professional counselors' offices should be constructed in correlative departments, which are chiefly under the charge of deans, along with the supervision of students' affairs office and major leaders in colleges.

The management in education. In the process of education, The test plays the role of a baton which guides students to develop gradually towards its definition of talents, Whether is it right or wrong? As to this question, the majority agree with it, who assure its positive aspects, for there is no a better measure up to now. This magic baton likes a magnet, which appeals tens of thousands of Chinese family to focus on education with unprecedented enthusiasm for the sake of children's future. To struggle to triumph in this direction, the students master a better knowledge during fierce competitions. We have to admit that this baton plays an important part in education.

We can take some trials: teachers should strengthen professional ethics personally, treat students' test scores with objectivity and impartiality. What's more, the students who require make-up examinations equally deserve objective and fair treatment. as a result,the above constructing suggestions should be relevant to the 
teachers' working assessment, which relieves the teachers' misgivings. There is still other transformation as following :cancel freshmen's arrangement in fixed classroom gradually, Change their old concept that the freshmen are necessarily constrained while the sophomore are desperately free. Besides, the teacher also needs to absorb new ideas, further implement school principles rigidly, and fully exhibit displines' power.

Employment. The current employment status of the universities throughout the country: supply---demand imbalance; high employment pressure.

While developing rapidly the training base, we should enhance the theoretical knowledge level of students , strengthen the quality and mastery education of them .In this way,comparing other higher vocational colleges, we can prominent the traits of our students: the higher theoretical knowledge level, better working ability, outstanding manipulative ability. So we can build the favorable image of model college, promoting the virtuous circle of employment, to be a model of employment indeed.

\section{Conclusions}

"Go along your road by yourself, cognitive the principles by yourself[10]." Academic conclusion must based on the own researches. Facing the current reconstruction of national model college.

\section{Acknowledgment}

Chongqing Vocational Institute of Engineering Research Foundation (JG142018).

\section{References}

[1] Y. Yaqin.Education sustainable development[J].Technology Square,2006,(3):115-116.

[2] G. Dacheng.Comprehensively implement the scientific concept of development and promote the healthy development of Higher Education[J].Studies on Higher Education in China,2006,(3):8.

[3] W. Zhengfu,Z. Zhiping. The struggle between modern education and traditional education and the trend of modern education[J].Journal of XiangFan University,2000,(6):77.

[4] H.Yanbin, Y.Binfang.Study the regional education for building the harmonious society service[J].Gansu agriculture, 2006,(2):210.

[5] Information on http://mall.cnki.net/magazine/article/KJCH200603053.htm.

[6] Z. Xiaobo,T. Jibi.On the humanistic quality education in Higher Vocational School[J].Scientific and technological achievements,2006,(3):79.

[7] C. Yuhua.Innovation or new[J].New curriculum teaching case,2008,(1-2):45.

[8] Y. Zhijiang,Y. Huipu.The connotation of innovation education and college students' Innovative Education[J].Gansu agriculture,2006,(5):248.

[9] W. Guoping.Modern education and future talents[J].Theoretical inquiry,2000,(11):12.

[10] Information on http://www.confucius2000.com/Confucian/fengzishu.htm. 